\begin{tabular}{|c|c|c|c|}
\hline \multirow{2}{*}{ 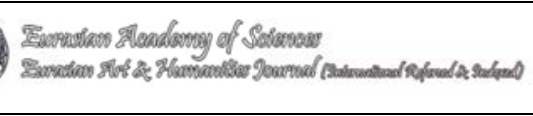 } & \multicolumn{3}{|c|}{$\begin{array}{l}\text { Eurasian Academy of Sciences } \\
\text { Eurasian Art \& Humanities Journal }\end{array}$} \\
\hline & 2015 & Volume:1 & S: $52-60$ \\
\hline \multicolumn{4}{|c|}{$\begin{array}{l}\text { Published Online April } 2015 \text { (http://arthum.eurasianacademy.org) } \\
\text { http://dx.doi.org/10.17740/eas.art.2015-V1-04 }\end{array}$} \\
\hline
\end{tabular}

\title{
Investigation of The Sign and Symbols of Trace Vladimir Nabokov's Philosophers Jacques Derrida Hypothesis of Adherence to Insanity silence
}

\section{ELIF SAKUT *}

\author{
Erciyes üniversitesi* \\ E-mail: elif_sakut@hotmail.com* \\ Received : 23 February 2015, ; Published : 5 April 2015
}

Copyright (C) 2015 ELIF SAKUT. This is an open access article distributed under the Eurasian Academy of Sciences License, which permits unrestricted use, distribution, and reproduction in any medium, provided the original work is properly cited.

\begin{abstract}
Nabokov is a miniature example of their experiences during migration 'Signs \& Symbols" is the subject of our study's silence in his madness. Our aim underlying a young person's disease, madness story will show how unlike literature and details of emotions experienced by the desire to escape the deathly silence of the embodied life is to figure out how to work has been characterized. In this study, Vladimir Nabokov's 1948 " Signs \& Symbols " short story analysis by way of literature and the similarities or differences between madness comparison method and the author of the migration period of the title was written, we examine the positivist analysis method. "Everything that the theme of that and everything is a password" believing an unstable young man, and the story is condensed to an old family of the struggle trying to cope with it by adhering to the madness of silence hypothesis, we try to identify with the said work.
\end{abstract}

Keywords: Nabokov,emigration, Signs and symbols,madness,silence

\section{Vladimir Nabokov'un İşaret ve Semboller Eserinde Filozof Jacques Derrida'nın Hipotezine Bağlı Kalınarak Delilik Sessizliğinin İncelenmesi}

ÖZET: Nabokov'un göç döneminde yaşadıklarının minyatür bir örneği olan "İşaretler ve Semboller' eserinde deliliğin sessizliği çalışmamızın konusunu oluşturur. Çalışmamızın amacı bir gencin hastalık hikayesinin altında yatan delilik, edebiyatın aksine nasıl gösterilir ve ölüm sessizliğinden uzaklaşmak için yaşanılan duyguların detaylarda somutlaştırılması yaşama arzusu ile nasıl karakterize edilmiş anlamaya çalışmaktır. Bu çalışmada Vladimir Nabokov'un 1948 yılında 'İşaretler ve Semboller"' başlığında yazmış olduğu kısa hikayeyi analiz yolu ile edebiyat ve delilik arasında benzerlik ya da farklılıklarını karşılaştırma yöntemi ve yazarın göç dönemini pozitivist inceleme yöntemi ile inceledik. "Her şeyin bir şifresi olduğuna ve her şeyin teması olduğuna " inanan dengesiz genç bir adamın ve onunla başa çıkmaya çalışan yaşlı bir ailenin mücadelesine yoğunlaşmış hikayesini delilik sessizliği hipotezine bağlı kalınarak söz konusu çalışma ile belirlemeye çalıştık.

Anahtar Kelimeler: Nabokov, Göç, “İşaret ve Semboller’, delilik, sessizlik. 


\section{Giriş}

Deliliğe her zaman hayran yazarlar vardır. Bunlardan biri de (1899 St. Petersburg-1977 Montreux) yirminci yüzyılın émigré ${ }^{1}$ yazarlarından Vladimir Vladimiroviç Nabokov'dur. “ Nabokov'un kendi eserleriyse, okurdan edebi hafiyeliğin de ötesinde, özel cerrahi yöntemler talep eder. İlk bakışta gördüğ̈̈müz derinin, yani yüzeyin altındaki kat kat dokunun, kas, sinir ve kemik yapısının ayırdına varmadan, incelemesini yapmadan, Nabokov'u anlamak mümkün değildir.", Kendisi işitsel ve görsel halüsinasyonlara ${ }^{3}$ maruz kalarak Nabokov birçok karakteri delilikle cazip hale getirerek oluşturmuştur.

Michel Foucault, "deliliğin tarihi" adlı yapıtında, deliliği şu yakıcı cümle ile tanımlar: "Delilik, insanın gerçekle olan ilişkisinin bozulduğu ve karardiğ yerde ortaya çıkmaktadır!" 4

Filozof Derrida ise şu sözlerle ifade eder: "Herhangi bir hayali ve tarihi yapının ötesinde delilik varsa, bu iş yokluğudur, daha sonra deliliği ortaya çıkarır, esas ve geneldir, sessizliktir, boğulmuş sestir. , ,5

Bu çalışmada Vladimir Nabokov'un 1948 yılında 'İ̧şaretler ve Semboller' başlığında yazmış olduğu kısa hikayeyi analiz yolu ile Derrida'nın bahsetmiş olduğu sessizlik ile deliliği ilişkilendiren hipotezine bağlı kalınarak edebiyat ve delilik arasında benzerlik ya da farklı1ıkları karşılaştırma yöntemi ve yazarın göç hayatı pozitivist yöntem ile incelenecektir.

Edebiyattın özgünlüğü deliliğin karşıtıdır. Edebiyat bazı yönlerden delilikle aynıdır fakat bazı yönlerden farklıdır da. Hem gerçeklik algısı hem de hayal dünyasının restorasyonu ile bağlantılı olarak anlam sorunun yanı sıra delilik ile edebiyatta karşılaşmak mümkün olabilir.

Deli, kısa hikayede oğlu olarak örneklendirildiği gibi dünyayı yorumlamaya çalışır. Bu hikaye okuyucuya deliryum $^{6}$ deneyimini andıran bir yorumlayıcı çılgınlığının bir kanıtını verebilir. Deliryum kelimesini etimolojik açıdan bildiğimiz gibi doğru anlamından saparak karakterize

\footnotetext{
${ }^{1}$ Émigré kelimesinin sözlük anlamı 'göç etmiş’ kişi olmakla beraber, politik sürgün manasında kullanılır. Franszıca kökenli bir sözcüktür, Nabokov eserlerinde émigré kelimesini kendisi için sıklıkla kullanmıştır. Anavatanı dışına göç etmiş kişiler için kullanılır.

${ }^{2}$ Yuri Leving Anatomy of a Short Story: Nabokov's Puzzles, Codes, Signs and Symbols,2012

${ }^{3}$ Halüsinasyon : Halüsinasyon, bir his organını uyaran hiçbir nesne veya uyarıcı olmaksızın, alınan bir hissin mevcudiyetine inanma halidir. Varsanı olarak da bilinir. Daha çok ruhsal ve sinirsel türdeki hastalıklarda karşılaşılan halüsinasyon, gerçekte olmayan fakat kişinin sahip olduğu 5 duyu organından herhangi bir tanesiyle algıladığını sandığı durumlara verilen bir isimdir.

${ }^{4}$ Foucault, Michel. Op.cit. History of Madness. New York: Routledge, 2006.

${ }^{5}$ Jacques Derrida op.cit Writing and Difference ,London ,1967, p 39

${ }^{6}$ Deliryum: Bilinç bulanıklığı ile giden bir beyin hastalığıdır. Özellikle hastanede yatan hastalarda görülür. Türkçe karşılığına yakın olarak da "delirme” tablosu gibidir. Konfüzyon, bilinç durumunda bozukluk, emosyonel labilite, halüsinasyonlar ya da ilüzyonlar ve uygunsuz, dürtüsel, gerçek dışı ve sert davranışlarla süren, akut, geri dönüşümlü mental bozukluktur.
} 
edilir, Latincede "sabanın toprakta açtığı iz ", anlamına gelen "lira”, ve “dışarı" anlamına gelen "de'" öneki ile türetilmiştir.

Edebiyat delilikten farklıdır, çünkü Derrida’ya göre o koşulsuz özgürlükle ifade edilir. Konuşma ise delilik içerisinde boğulmuş ve serbest olmalıdır. "Delilikle diyalog kurmayı deneyin, bu bir yaklaşımdır fakat yaşayabilmek için ondan uzaklaşmak gerekir. ."7 Deliliğin metin ile ayrıcalıklı bir ilişkisi vardır, metnin altında yatan tematik karşılığının yerine sadece bir metafordan çok daha fazlası olabilir.

Biz hikayenin sonunda kimin telefon ettiğini bilemeyiz bu onun gizemliliğinin deli olmasında yatar, oğlu aklı başında insanlarla iletişim kuramamaktadır.' Bir deli akıllıya çok şey ögretir ama bir akıllı bir deliye hiçbir şey ögretemez "diyen İngiliz filozof A.N.Whitehead gerçek bilgeliğin delilik olduğundan bahseder. Deli, tutunmanın ne kadar aptalca bir şey olduğunu öğretebilir. Deli gurbette olduğumuzun en büyük sembolüdür. İnsanoğlu Mevlana'nın da dediği gibi sazlıktan kopmuş bir ney parçası gibidir. Deliler hiçbir şey üretemezler. Çünkü deliler dünyanın ciddiye alınmayacak kadar basit bir yer olduğunu biliyorlar. Bunu bildikleri için kendilerini deliliğe verirler. Bu hikayede oğlu tarafından intihar girişimi haricinde hiçbir şey olmuyor. Aile ise tam tersine karar ve seçim yapar: onlar oğlu için doğum günü hediyesi seçer, oğlunu eve götürmeye karar verir. Oğlu dalgın ve sessizdir, hiçbir şey söylemez , hiçbir şey yapmaz. Oğlunun bize gösterdiği gibi “onun dünyasının içinde bir delik gözyaşı olmak ve kaçmak isterdim ", ifadesiyle delilik sembolik bir cezaevidir. Eğer patolojik delilik geceye bağlı ise ve gece ölümün yaklaştığına tekabül ediyorsa , gündüz akıl için yaşam arzusudur.

Halihazırda olan sessizlik hepimizin bildiği anlamıyla sessizliktir. Sessizlik; sesin olmama durumu, huzurlu ve herkesin ihtiyaç duyduğu bir olgu olarak algılanır. Çoğu zaman sorunsuzluktur. Kısaca sessizliğin düşündürdükleri, sessizliğin iyi ya da kötü hissettikleri , sessizliğin olduğu durumlar ve sessizlik hakkında söylenenler ya da yazılanlar sessizlik bilgisini oluştururlar.Adam Jaworski'ye göre sessizlikle ile ilgili incelemelerde "dilbilimsel ya da etnografik çalışmaların ă̆ırlı̆̆l söz konusu olsa da göstergebilimsel, pragmatik, ĕgitime yönelik, edebî ve felsefi sessizlik çalışmalarının da alana katkısı yadsınamaz." "9öz konusu olan dilin olanaklarını ve sınırlarını, yani onun neyi söze döktüğünü, neyi sessizlikle geçiştirdiğini bilmektir. Sessizliği anlamını bilmek onu soyut bir gösterge olarak tanımlayabilmek, belirti-sessizlik ile simge-sessizlik arasındaki farkı kavrayabilecek durumda olmaktır. Onun neleri belirttiğini tanımaktır. Aynı sessizlik, aynı toplumsal ve kültürel çevreden olmayan iki kişi tarafından değişik biçimlerde anlaşılabilir. Her biri bu sessizliğe kendi kültürel değerlendirmelerini uygulayacaktır.

Sessizlik kelimesinin Latince kökeni, silere, hiçbir şey söylememek ise, sinere, bir yerde olmaya izin verme ile ilişkilidir. Kuşkusuz sessizliğin pek çok ve çeşitli tarafları vardır. Çoğu kez ilişsili durumlar olan korkunun, kederin, uyumun, karmaşanın maruz kalınan veya

\footnotetext{
${ }^{7}$ Jacques Derrida op.cit Writing and Difference, London ,p 74.

${ }^{8}$ Владимир Набоков. Знаки и символы, Бостон, 1948

${ }^{9}$ Adam Jaworski, The Power of Silence ,1992
} 
gönüllü sessizlikleri (örn. "Sessizlik=Ölüm” formülasyonu) vardır. Gerçeğe dönersek, tabiat sessizlikler ile doldurulur. Mevsimlerin birbirini izleyişi sessizliğin ritmidir; geceleri, günümüzde çok daha az olsa da, gezegen üzerine sessizlik çöker.

"Delilik ve sessizlik rahatsı edici kuzenlere benzetilebilir." ${ }^{10}$ Her ikisi şüpheli veya negatif unsurları rasyonel iletişim ve diyalog ideallerini tanıtır. Sessizlik rahatsız edebilir ve gerçeğin peşinde rasyonelleri bozabilir, delilik fikir ve düşüncelerin karşılıklı değişimi gürültülü bir provoke olabilir.

Deli karakter, yaşadığı dünyaya uyum sağlayamayan birey, deli yazar ise susturulan kitleler adına söyleyecek sözü olan kişidir. Bu sebeple deli artık kliniklere kapatılan hasta değil, sözcüklerin içinden geçerek sesini bulan kişidir.

Sessizlik ile karşılaştırıldığında felsefenin şöhreti sönüktür, genel anlamada filozofların sessizlik hakkında görüşleri şöylerdir: "Aristoteles sessiz olmanın mide gazına sebep olduğunu iddia ederken, Sokrates sessizliği bir saçmalık alanı olarak suçladı (...)Hegel konuşulamayan şeyin tamamen yanlış olduğunu, sessizliğin üstesinden gelinmesi gereken bir kusur olduğunu açıkça belirtti. (...) Derrida sessizliği düşüncenin nihilist düşmanı olarak suçlayarak ilkel ve ön mantıksal sessizliğin şiddetini sertçe kınadı. "11 Derrida ve özellikle postmodernizm konuşmadaki araya giren sessizlik anlam engeli olduğunu ileri sürerek, dilin yetersizliğinin reddeder. Aslında Derrida, sessizliğin şiddetini kınar.

Sessizlik insanın dünyadaki yolculuğunu anlatır. Kendi ekseni etrafında dönüp yine başladığ yere varan bir hareketin sesinden bahseder. Sessizlik insanı kendi özüne döndürür, kendi ile tanışık hale getirir ve bir anlamda kendi iç sesini duymasını sağlar.Sessizlik yoluyla ulaşılabilir olan yalnızca doğal dünya değildir. Cioran, "tüm nesnelerin, yalnızca tam bir sessizlikte çözebileceğimiz bir dile sahip oldukları"12 sonucuna vararak, eşyanın sessizliğindeki sırlara işaret etti.

Zaman sessizlikte artar; akmıyor, ancak katlanıyor görünür. Sessizlik bunun hepsine bir sitemdir ve kendimizi yeniden oluşturmak için bir bölgedir. En derin tutkular sessizce ve derinliklerde beslenir. Ölü için saygıda en belirgin şekli ile sessizlik kendini ifade eder. Sessiz kalınca insan; iletişim kopar, bütün anlaşmalar karmaşıklaşır ve zorlaşır. Ama hayat kurtarır bazı zaman duymayı istemediğin şeyleri duymamanı sağlar.

“İşaretler ve Semboller ” Vladimir Nabokov’un göç döneminde yazdı̆̆ı genç bir adamın ağır zihinsel halsizlik hastalığı ve onunla başa çıkmaya çalışan yaşlı bir ailenin mücadelesine yoğunlaşmış bir hikayedir. Kısaca bahsedecek olursak:

Cuma günü Amerika'nın büyük bir şehrinde sanatoryumdaki yirmi yaşında bir gencin doğum günüdür. O "yanılgı sistemi " adındaki hastalıktan muzdariptir. 20 yaşındaki oğlu psikiyatri hastanesinde 4 yıldır tedavi görmektedir. İnsan yapımı nesnelerin kendisine karşı komplo

\footnotetext{
${ }^{10}$ Alexander E. Hooke The Most Silent of Men: Nietzsche's Other Madness 2003, Journal of Phenomenological

${ }^{11}$ Aristotle, Works of Aristotle, çeviren S. Forster, Vol. VII, Problemata (Oxford: Clarendon Press, 1927), s. 896, satır 20-26.

${ }^{12}$ Emile M. Cioran http://www.brainyquote.com/quotes/quotes/e/emilemcio400809.html
} 
olduğunu iddia eden bir hastalığı vardır. Örneğin, bulutların diğerleri ile bilgi alışverişi yaptığının hayalini kurar, geceleri ağaçların onun derin düşüncelerini iletmek için işaret dilini kullanır. Genç adam kendisi tarafindan algılanan nesnelerden korkar bu yüzden aile oğlu için doğum günü hediyesi seçme problemi ile karşı karşıyadır. Aile on küçük kavanoz içerisinde on farklı meyve jölesi olan bir sepet almakta karar kılar. Hastaneye vardıklarında aile ile genç adamın görüşmesine izin verilmez çünkü oğulları intihara teşebbüs etmeye çalışmıştır. Eve döndükleri zaman akşam yemeğinden sonra baba yatak odasında dinlenmeye çekilmiş, anne ise fotoğraf albümünü incelemektedir.Gece yarısından sonra baba oturma odasına geri gelir ve oğlunu eve getirmek istediğini açıklar. Konuşmanın ortasında telefon çalar. Bu yanlış numaradır. Bir kız Çarli ile konuşmak istediğini söyler.Sonra onların konuşması aynı kızdan gelen telefonun çalması ile kesilir.Anne kıza neden yanlış bir numara olduğunu açıklar ve çift gece yarısı çay içerler.Baba kavanozları inceler, etiketleri heceleyerek okurken tekrar telefon çalar.Ve hikaye böyle sonlanır .

Telefonun zil sesi sessizlikle aşılanmış bir hikaye içerisinde araya girme gibidir. Üç bölüme ayrılır, hikayenin son bölümünde doğrudan konuşmanın içinde bir konuşmadan diyalog sunar. Anlatıcı anne ve baba arasındaki dolaylı konuşmayı kullanır, ya da hemşire ile aile arsındaki. Sessizlik sık sık seslerin algısı ile oluşturulur. Onlar hastaneden gitmek için yeraltında tren beklerler tek kelime etmezler "herhangi biri sessizlikte hiçbir şey duyamaz fakat kişinin kalbinin atışııın sesini duyabilir ve gazete hışırtısını." ${ }^{13}$ Eve geldiklerinde akşam yemeği vaktinde ev "sessizlik içindeydi”, oğlunun hastalığı ailenin dünyasının kaderine boyun eğmiş bu atmosferin karakterinin kökenini oluşturuyordu.

Daha sonra biz ironik olarak bilgilendiriliriz "onun hayal sistemi aylk bilimsel ayrnntıl bir kağıdın konusu olmuştur" 14 ve bu German Brink tarafindan "heyecandan depresyona geçiş olan yanılgı sistemi -Мания упоминания" 15 olarak adlandırılmıştır. Çok nadir görülür yanılgı sistemdir, etrafinda olup biten her şeyin onun hayalindeki kişiliği ve varlığ ile örtülü olan bir referanstır. Hikayede ilk ve son cümle dikkat çekicidir "her şey onun etrafinda olur , onun kişiliği ve varlığ ile örtülü referanstır" ve "her şey bir şifredir ve her şeyde o temadır." ${ }^{16}$ Hasta onun merkezinde ve hedefinde olan kapalı bir dünyada yaşadığını hayal eder. Kendisini diğerlerinden üstün hisseder ve zulmeden dünyaya düşmanlık besler.

Bir çiftin yaşamı kısa bir güne kısaltılmış olmasına rağmen, bekleyen hafıza tarafından uzatılır, kısa hikaye bu nedenle bir zaman aralığı içerisinde yaşanmaktadır. Sürekli bekleyiş̧ içerisinde olan çift, arıza olduğu için yer altı trenini bekliyor, hemşireyi bekliyorlar. Onlar belirsizlik ve geleceğin tehdidi ile delilik sessizliğinde karşı karşıyadırlar. Aslında hikaye üç başarısız iletişim etrafinda döner : onun dünyasını anlamak için oğlunun başarısızlığı, oğluna ulaşmak için ailenin başarısızlığı, arayan yanlış numara.

\footnotetext{
${ }^{13}$ Владимир Набоков. Знаки и символы, Бостон, 1948

${ }^{14}$ Владимир Набоков. Знаки и символы, Бостон, 1948

${ }^{15}$ Vladimir V .Nabokov. "Signs and Symbols." 1948. In Nabokov's Dozen: Thirteen Stories. 1960. London: Penguin. (Abbreviated as SS)

${ }^{16}$ Владимир Набоков. Знаки и символы, Бостон, 1948
} 
Nabokov'un tüm yaşadıklarında eserlerinde kendi hayatının minyatür versiyonlarını dahil etme yeteneği ile karşılaşıyoruz. Eğer onun kişisel hayatını biliyorsanız eserlerde hayatı küçük detaylar içinde göze çarpıyor. Bu yüzden bu eseri incelememize en uygun olacak yöntemin pozitivist yöntem olduğuna karar verdik. İşaret ve sembolleri pozitivist yöntemle inceldiğimizde bizde tatlı acı bir his uyandırır, çünkü Nabokov'un yaşamından çeşitli detayları içerir özellikle göç hakkında, Avrupa'dan yaptığı göç, Almanların elinde ölen akrabaları ve teyzesi Roza, babasının ırkçı iki faşistin bir arkadaşına saldırısını önlemek isterken öldürülmesi hepsi Nabokov'un eserlerinde karşılaştı̆ğımız birer minyatür örnektir. Bu yöntemi kullanmamızdaki amaç yazarın yaşantısının esere olan yansımasını ortaya koymaktır.

\section{Malzeme ve Yöntem}

“Işsaretler ve Semboller " Vladimir Nabokov’un göç döneminde yazdı̆̆ genç bir adamın ağır zihinsel halsizlik hastalığı ve onunla başa çıkmaya çalışan yaşlı bir ailenin mücadelesine yoğunlaşmış hikayesi malzememizi oluşturmaktadır.

Araştırma yöntemi olarak Vladimir Nabokov'un 1948 yılında 'İşaretler ve Semboller', başlığında yazmış olduğu kısa hikayeyi analiz yolu ile Derrida’nın bahsetmiş olduğu sessizlik ile deliliği ilişkilendiren hipotezine bağlı kalınarak edebiyat ve delilik arasında benzerlik ya da farklılıkları karşılaştırma yöntemi ile incelenmiştir. Nabokov'un göç hayatından yola çıkarak kaleme almış olduğu eserde pozitivist inceleme yöntemi kullanıllmıştır. Ayrıca Rita Felski'nin hayat-metin-hayat teorisi göz önüne alınarak yazar Nabokov”un göç döneminde yaşadığı olayların eserde nasıl yer bulduğuna dair ifadelere yer verilmektir.

\section{Bulgular}

Nabokov bir gencin hastalık hikayesini ve onunla başa çıkmaya çalışan ailenin mücadelesini anlatmıştır. Nabokov okurun roman kişisi ile özdeşleşme eğilimine karşı bir edebî tutum benimsemiştir. Yazar Sartre'nin öncüsü olduğu anti-roman akımına benzer eserler yazmıştır.Bu eserlerden biri de İşaret ve Semboller'dir.Yazarın kendini romana katmasını sağlamış, zamanı ileriye ve geriye sıçratarak ele almış ve kendini kahramanla özdeşleştirmeye çalışmıştır.Nabokov'un eserinde kimlik, sürgün konuları hakkında hatıralara da yer vermiştir. Almanların elinde ölen teyzesi Roza'yı, annesinin istasyonda gördüğü kızı ona benzetmesi ile esere yazarın hayatını dahil ettiğini görürüz. Nabokov'un en incelikli otobiyografik eserlerinden biri olan İşaret ve sembollerde farklı ülkelerde, farklı şehirlerde yaşadığı yıkımla birlikte, Devrim Rusyası, Hitler Almanyası, korkunç savaşlar, en sevdiği kardeşinin ölümü, Yahudi karısı Vera'yla yaşadıkları yerlerden kaçmak zorunda kalmaları deliliğin uçurumundan aşağıya bakan gencin hikayesinde izler taşımaktadır.

Okuyucu yazarın geçmişinin farkındadır, anılara boğulmuş fotoğraf albümünü inceleyen anne gibi Rusya ve Almanya kişisel hatırları, sürgün ve göç, aynı zamanda oğlunun farklı 
yaşlardaki anılarıdır. Her fotoğraf onun hastalığının ilerlemesinde bir adıma karşılık gelir. Bu yüzden, o çocukken "diğer çocuklardan çok daha fazla şaşırmlş gözükürdü", "Dört yaşında hayvanlardan korkardl, altı yaşında insan el ve ayakları ile harika kuşlar çizdi ve uykusuzluktan acı çekiyordu " "18 Sonra fobilerden muzdaripti. Fotoğraflar aracılığı ile anne oğlu büyüdükçe görünen semptomları onun hastalığının habercisi olan şeyleri merak etmeye başlar. Hasta için artık zaman olmamasına rağmen, hastalığı tam olarak teşhis edilememiş ya da adlandırılamamıştır. Nabokov'un yaşamının sonunda hastalığı teşhis edilememiştir.

Kısa hikaye belirli bir zaman dilimi içerisinde genişleyen gerçek olay olduğunu göstermektedir. Okuyucuya metnin içerisinde gizemli bazı bilgiler verir. Örneğin, hikayenin sonunda çalan telefonun kimden veya nereden geldiği merak edilebilir. Gerçekten yanlış numara mıydı yoksa oğullarının öldüğ̈ haberini vermek isteyen hastaneden mi geliyordu bilmiyoruz. Nabokov'un çalışmalarında yaşamın ve dünyanın büyülü güzelliklerinin farkında olması "merak" kelimesi ile ilişkilidir. Böylece hastanın hiçbir arzu ve merakı olmamasına rağmen, Nabokov'un yaşam için savunmasıyla uygun olarak hasta ile aile arasında bir umut vardir.

Hikayenin başlığında belirtilen "Semboller"okuyucuyu deşifre etmek için oluşturulan işaretlerdir. Hikaye boyunca tekrarlanan detaylar sayesinde ölüm haberini anlıyoruz . Annenin siyah elbise giymiş olması, Naziler tarafindan öldürülen akrabalarının fotoğrafına bakması, eve dönerken onun intihar girişiminde bulunduğu zaman uçmaya çalıştığından haberdar olduğumuz gibi oğlunu çağrıştıran "küçük ölü bir kuşla" karşılaşmaları bir nevi ölümün habercisidir. Kuşlar ise bir kişiden, tanrıdan ya da insanlardan iletişim için kullanılan geleneksel bir semboldür.

\section{Sonuç}

Sonuç olarak bu hikaye ile bir gencin hastalık hikayesini pozitivist yöntemle inceleyip altında ya da arkasında ya da içinde başka bir hikaye olabilir hipotezini görmekteyiz. Eserde yazarın geçmişinin anılara boğulmuş fotoğraf albümünü incelemesi, Rusya ve Almanya kişisel hatırları, sürgün ve göç, aynı zamanda oğlunun farklı yaşlardaki anıları sayesinde yazarın hayat-eser ilişkisini görmemizi sağlamıştır. Eseri dikkatle okuduğumuzda delilik sessizliğinin satırlar arasında nasıl hükmettiğini hissediyoruz. Sessizlikle birlikte delilikten bahsederken söz edemediklerimizi düşünmeye başlıyor, cinnet sorusunun tüm detaylarını görüyor ve aslında deliliğin en yoğun halinin sessizliğin içinde saklandığını anlıyoruz. Delilik bütün sessizliklerin altındaki sestir, kimi zaman korkuya gelince bir zittı olmayan umuttur, güçtür öylesine kuvvetli ki onun yanında gücün kendisi kuvvetsiz kalır, güneşten daha önce, yıldızdan sonra gelen gerçekliktir, süresi olmayan uçsuz bucaksız bir bekleyiştir.Bir gencin hastalık hikayesinin altında yatan delilik, edebiyatın aksine nasıl gösterilir ve ölüm sessizliğinden uzaklaşmak için yaşanılan duyguların detaylarda somutlaştırılması yaşama arzusu ile nasıl karakterize edilmiş anlamaya çalıştık.

\footnotetext{
${ }^{17}$ Владимир Набоков. Знаки и символы, Бостон, 1948

${ }^{18}$ Владимир Набоков. Знаки и символы, Бостон, 1948
} 


\section{REFERENCES}

- Набоков Владимир, Знаки и символы, Бостон, 1948

- Derrida Jacques op.cit Writing and Difference ,London ,1967

- E. Hooke Alexander, The Most Silent of Men: Nietzsche's Other Madness, 2003, Journal of Phenomenological

- Berthold-Bond Daniel,Hegel's Theory of Madness, STATE UNIVERSITY OF NEW YORK 1995

- Foucault, M. Deliliğin Tarihi, Çev. Mehmet Ali Kılıçbay, Ankara: İmge Kitabevi, 2000.

- Boyd Brian, Vladimir Nabokov: The Russian Years. Princeton, New Jersey: Princeton University Press, 1990.

- Mark Zvi , Mysticism and Madness: The Religious Thought of Rabbi Nachman of Bratslav,2009

- Gann Kyle , Cage John Silence: Lectures and Writings, 50th Anniversary Edition Wesleyan University Press Middletown, Connecticut, 1961

- Roy Johnson Signs and Symbols a critical examination of Nabokov's collected stories,2005, http://www.mantex.co.uk/2009/09/26/signs-and-symbiols/ 